\title{
Boceprevir in the treatment of chronic hepatitis $C$ virus infection
}

\author{
This article was published in the following Dove Press journal: \\ Virus Adaptation and Treatment \\ 22 February 201I \\ Number of times this article has been viewed
}

\author{
Marina Berenguer ${ }^{\prime}$ \\ F Xavier López-Labrador ${ }^{2,3}$ \\ 'Hepatology-Liver Transplantation \\ Unit, Digestive Medicine Service, \\ Hospital Universitari La Fe, and \\ National Network Center for \\ Hepatology and Gastroenterology \\ Research, Instituto de Salud Carlos III, \\ CIBEREHD Spain; ${ }^{2}$ CSISP, Center for \\ Public Health Research, Public Health \\ Department, Generalitat Valenciana \\ and Microbioloy Department/ \\ Institut Cavanilles, University of \\ Valencia, Valencia, Spain; ${ }^{3}$ National \\ Network Center for Biomedical \\ Research in Epidemiology and Public \\ Health, Instituto de Salud Carlos III, \\ CIBERESP Spain
}

\begin{abstract}
Chronic hepatitis $\mathrm{C}$ virus (HCV) infection is a global public health problem. The current standard-of-care treatment is effective in about $40 \%-50 \%$ of the cases, and the infection progresses to end-stage liver disease, hepatocellular carcinoma, and liver failure in a considerable number of infected individuals. After end-stage liver disease is established, the only reliable therapeutic intervention is liver transplantation. The urgent need for new, effective therapies is now focused on specific inhibitors of viral enzymes, among which inhibitors of the viral NS3/4A serine protease and NS5b RNA-dependent RNA polymerase are the most advanced in clinical development. In particular, telaprevir and boceprevir have entered several Phase III clinical trials after promising Phase II results. This review summarizes the preclinical and clinical development of boceprevir, one of the most important HCV NS3/4A protease inhibitors, and the eventual impact of this new inhibitor class for future HCV therapies.
\end{abstract}

Keywords: HCV, antiviral therapy, protease inhibitors, viral resistance

\section{Introduction}

Current standard-of-care (SOC) therapy for chronic hepatitis $\mathrm{C}$ virus (HCV) infection is based on the combination of pegylated interferon alfa (peg-IFN $\alpha$ ) and ribavirin (RBV). ${ }^{1}$ These drugs are not direct-acting antivirals (DAAs) but rather immunomodulators, although RBV may act by more than one mechanism, including modulation of the immune response and an increase in the mutation rate of the $\mathrm{HCV}$ genome. ${ }^{2,3}$ The efficacy endpoint of this treatment is eliminating viral replication (absence of detectable HCV RNA in serum) 24 weeks after the end of treatment (sustained virological response [SVR]). Almost all patients who achieve SVR remain virus-free after 5 years of follow-up and are considered to be cured from the infection. ${ }^{4} \mathrm{HCV}$ eradication results in histological and clinical improvements with regression of fibrosis, decreased risk for hepatocellular carcinoma if cirrhosis was present, and overall reduction of morbidity and mortality associated with chronic infection. ${ }^{5}$ The rate of treatment success depends on the infecting viral genotype, among other factors, such as the stage of liver fibrosis, coexistence of a metabolic syndrome, age, and host genetics. ${ }^{6}$ Indeed, the strongest predictor of treatment response has been identified recently, implicating a genetic polymorphism in the interferon lambda-3 gene $I L 28 B$. The more favorable genotype is rs $12979860 \mathrm{C} / \mathrm{C}$, which is more common in Asians and Caucasians than in African Americans, possibly explaining the worse SVR rates achieved by African Americans in most studies. ${ }^{7}$ Regardless of the IL28B genotype, in patients infected with HCV genotype 1, SVR is about $40 \%$, whereas it ranges from $60 \%$ to $80 \%$ in those infected with genotypes 2 and 3. ${ }^{1}$ Treatment compliance is complicated because side
Correspondence: F Xavier López-Labrador CSISP, Center for Public Health

Research, Public Health Department,

Generalitat Valenciana, Av. Catalunya 2I, 46020 Valencia, Spain

Tel +34-96-1985839

Fax +34-96-1925703

Email f.xavier.lopez@uv.es 
effects are common and include flu-like syndrome, anemia, rash, cough, and depression. Serious adverse events (AEs) are uncommon but may result in the death of the patient. Dose reductions are required in a third of cases, particularly with RBV, but treatment discontinuation due to AEs is a rare event (about 5\%). Unfortunately, dose reductions greater than $80 \%$, particularly of RBV, as well as treatment discontinuation before $80 \%$ of the treatment course, reduce the chance of achieving an SVR. ${ }^{6}$

In recent years, the unavailability of an effective therapy, the predicted increase in the burden of advanced liver disease due to HCV expected for the years to come, and new insights into $\mathrm{HCV}$ virology have led to an unprecedented advance in the development of investigative Direct Acting Antivirals (DAAs) against critical steps of the HCV life-cycle. The establishment of cell culture systems based on HCV subgenomic replicons ${ }^{8}$ and the development of a culture system to reproduce the complete viral life-cycle in vitro, based on chimerical viruses, ${ }^{9,10}$ allowed in vitro testing of newly developed inhibitors of HCV enzymes such as the HCV NS3/4A protease and the NS5b RNA-dependent RNA polymerase. The first-generation protease inhibitor (PI) was developed by Boehringer Ingelheim, Ingelheim, Germany (BILN-2061, ciluprevir), establishing proof of concept for the efficacy of these types of compounds, ${ }^{11}$ but, after Phase I studies, further development was halted because of cardiotoxicy concerns. ${ }^{12}$ The inhibition of the NS3/4A protease interferes with the virus life-cycle, impeding the processing of the viral polyprotein, and probably restores the pathways of the innate immunity. ${ }^{13}$ Several HCV NS3/4A PIs were soon developed (Table 1), such as VX-950 (telaprevir [Vertex Pharmaceuticals, Cambridge, MA]),

Table I Most advanced direct-acting antivirals in clinical trials for the treatment of chronic hepatitis $C$ virus infection

\begin{tabular}{lll}
\hline Drug & Company & $\begin{array}{l}\text { Development } \\
\text { phase }\end{array}$ \\
\hline $\begin{array}{l}\text { Telaprevir (VX-950) } \\
\text { Boceprevir (SCH503034) } \\
\text { ABT-450 }\end{array}$ & $\begin{array}{l}\text { Vertex Pharmaceuticals } \\
\text { Merck }\end{array}$ & $\begin{array}{l}\text { Phase III } \\
\text { Phase III }\end{array}$ \\
BI-20I335 & Abbott/Novartis & Phase II \\
BMS-650032 & Boehringer Ingelheim & Phase II \\
BMS-79I325 & Bristol-Myers Squibb & Phase II \\
GS-9256 & Bristol-Myers Squibb & Phase II \\
Danoprevir & Gilead & Phase II \\
(ITMN-19I/RG7227) & InterMune/Roche & Phase II \\
TMC435350 & & \\
Vaniprevir (MK-7009) & Tibotec/Medivir & Phase Ila \\
Narlaprevir (SCH 9005I8) & Merck \& Co & Phase II \\
with or without ritonavir & & Phase II \\
\hline
\end{tabular}

SCH-503034 (boceprevir [Merck \& Co, Kenilworth, NJ]), ITMN-191, TMC435350, MK-7009, ACH-806 (GS-9132), and others. ${ }^{14-23}$ Among those that progressed to later stages of development, the most advanced are telaprevir (Vertex Pharmaceuticals) and boceprevir (developed by Schering-Plough, Kenilworth, NJ a company now combined with Merck and Co.), and their approval for treatment of both treatmentnaïve and treatment-experienced patients is expected by late 2011/2012. ${ }^{24}$ Merck plans to submit a New Drug Application for boceprevir to the US Food and Drug Administration on a rolling basis and expects to complete regulatory submissions in the US and EU during 2011. ${ }^{25}$

\section{Boceprevir Pharmacology}

\section{Mode of action}

Figure 1 shows examples of the two classes of $\mathrm{HCV}$ NS3/4A oral PIs: i) noncovalent peptidomimetic derivatives ciluprevir and ITMN-191 and ii) covalent reversible inhibitors telaprevir and boceprevir. Boceprevir (SCH503034) is a carboxamide-based HCV NS3/4A oral $\mathrm{PI}$, an $\alpha$-ketoamide providing effective inhibition through a stable, covalent, and reversible complex with the viral enzyme. Boceprevir reacts with the $\operatorname{Ser}^{139}$ of the active site (serine trap inhibitor), compromising the catalytic triad His $^{57}-\mathrm{Asp}^{81}-\mathrm{Ser}^{139} .{ }^{26}$ The equilibrium binding constant $\mathrm{Ki}$ in cell-free assays was $14 \mathrm{nM}$ and the concentration that produces a $50 \%$ effective response $\left(\mathrm{EC}_{50}\right)$ and $\mathrm{EC}_{90}$ in 72 hours. HCV replicon assays (subtype 1b) was $200 \mathrm{nM}$ and $350 \mathrm{nM}$, respectively. ${ }^{26}$ In cell culture, boceprevir suppressed HCV replicon synthesis with a concentration that produces $50 \%$ inhibition $\left(\mathrm{IC}_{50}\right)$ and $\mathrm{IC}_{90}$ values of $200 \mathrm{nM}$ and $400 \mathrm{nM}$, respectively. ${ }^{16}$ The antiviral activity was unaffected by the addition of IFN $\alpha .^{16}$

\section{Pharmacokinetics Preclinical}

The pharmacokinetic profile evaluated in animals following oral administration showed a more modest bioavailability in monkeys (4\%, maximum concentration $\left.\left[\mathrm{C}_{\max }\right] 0.09 \mu \mathrm{M}\right)$ than in rats or $\operatorname{dogs}\left(26 \%, \mathrm{C}_{\max } 0.66 \mu \mathrm{M}\right.$ and $30 \%, \mathrm{C}_{\max } 2.3 \mu \mathrm{M}$, respectively), but a target organ analysis in rats showed a 1:30 plasma/liver concentration ratio. ${ }^{26}$

\section{Clinical}

In Phase I trials, boceprevir was absorbed rapidly in healthy volunteers in doses ranging from $50 \mathrm{mg}$ to $800 \mathrm{mg}$ after oral 
A

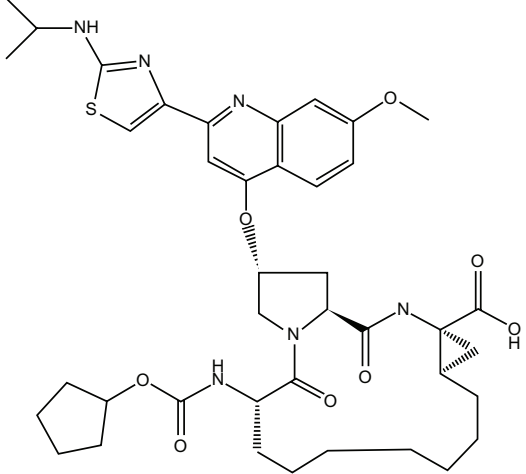

Ciluprevir

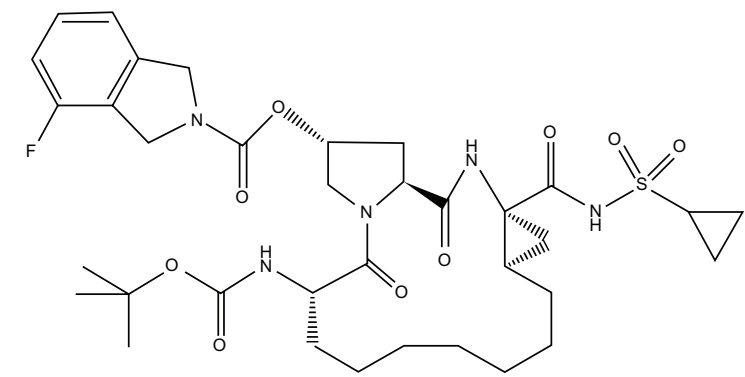

ITMN-191

B<smiles>CC(C)(C)[C@H](NC(=O)C(NC(=O)c1cnccn1)C1CCCCC1)C(=O)N1C[C@H]2CCC[C@H]2C1C(=O)NCC(=O)C(=O)NC1CC1</smiles>

Telaprevir

C

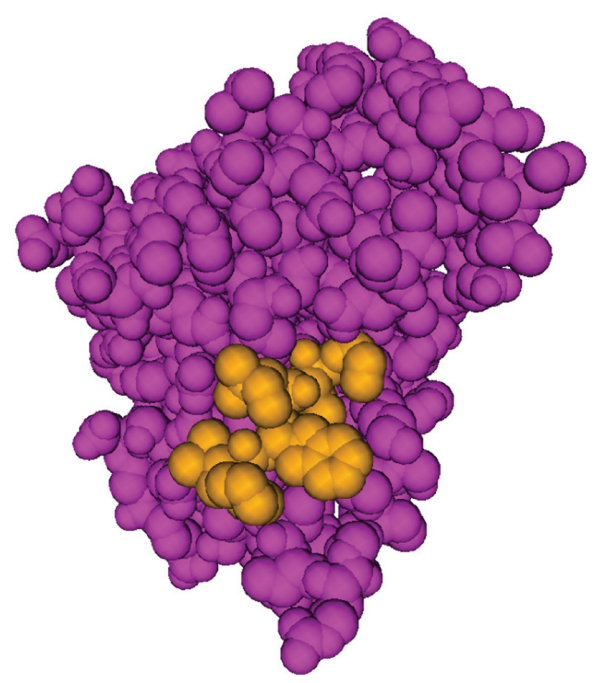

Figure I Examples of macrocyclic (A) and ketoamide (B) inhibitors of the hepatitis C virus NS3 protease. C) shows one molecule of one boceprevir derivate (yellow) docked to the NS3 protease substrate (purple), constructed using the structure deposited in public databases (PDB ID 3KN2).

administration. Time to maximal concentration $\left(\mathrm{t}_{\max }\right)$ values ranged from 1 hour to 2.25 hours, and plasma concentrations declined with an elimination half-life $\left(t_{1 / 2}\right)$ from 7 hours to 15 hour. ${ }^{27}$ Safety profiles of boceprevir and placebo in healthy volunteers were similar. ${ }^{27}$ Boceprevir was also rapidly absorbed, and values of $t_{\max }$ were similar in SOC treatment-experienced patients (previous nonresponders) after oral dosing of 100-400 mg twice or $400 \mathrm{mg}$ three times daily. ${ }^{28}$ In a multiple-dose, three-way crossover, Phase I study in patients with genotype $1 \mathrm{HCV}$ infection, $\mathrm{C}_{\max }$ and $t_{\max }$ values of boceprevir were $351 \mathrm{ng} / \mathrm{mL}(675 \mathrm{nM})$ and 1 hour or $523 \mathrm{ng} / \mathrm{mL}(1 \mu \mathrm{M})$ and 1 hour 8 days after administration of three times daily $200 \mathrm{mg}$ or $400 \mathrm{mg}$ doses, respectively. ${ }^{29}$ 


\section{Metabolism and drug interactions}

There is interest in enhancing the bioavailability and/or pharmacokinetics of HCV NS3/4A PIs such as boceprevir. In the case of human immunodeficiency virus (HIV), some PIs, such as etravirine, are metabolized by cytochrome P450 and have the potential for drug interactions with coadministered medications. Coadministration with an inhibitor of cytochrome P450 monooxygenase, such as ritonavir, improves the pharmacokinetics of HIV PIs and their duration of action. ${ }^{30}$ Because HCV PIs resemble inhibitors of HIV protease, and cytochrome P450 isoenzyme 3A4 (CYP3A4) is the predominant cytochrome in the liver, boceprevir bioavailability can be potentially increased, when inhibiting CYP3A4 activity. The interaction of boceprevir and telaprevir with ritonavir, an CYP3A4 inhibitor, was studied in vitro in human liver microsomes and in vivo in rats. ${ }^{31}$ The metabolism of both drugs was strongly inhibited by the presence of ritonavir and, on codosing in rats, plasma exposure of the HCV PIs was increased by $>15$-fold, and plasma concentrations 8 hours after dosing were increased by $>50$-fold..$^{31}$ Thus, there is a rationale for exploring coadministration of boceprevir (and other HCV PIs) with CYP3A4 inhibitors such as ritonavir. In fact, a favorable increase in pharmacokinetics has been observed in a Phase Ib clinical trial (Protocol No. P04695, NCT01081158) to assess the safety, tolerability, pharmacokinetics, and pharmacodynamics of the more potent second-generation NS3 PI SCH-900518 (narlaprevir) coadministrated with ritonavir. ${ }^{32}$

In patients with $\mathrm{HIV} / \mathrm{HCV}$ coinfection, there is an accelerated course of the HCV disease, and SOC treatment outcomes are more disappointing compared with HCV monoinfected patients. Some drug interactions between boceprevir, telaprevir, and antiretrovirals may occur because the aforementioned data suggest that HCV PIs and HIV PIs may share common metabolic routes through CYP3A4. Whereas some HIV PIs (ie, lopinavir and darunavir) inhibit CYP3A4, their effect may in fact be an inhibitory action on coadministered ritonavir boosting. ${ }^{30}$ Thus, such types of interactions, if appropriately managed, could allow for potential dual boosting of both HCV and HIV PIs in coinfected individuals but will require careful management. Seden et al have recently reviewed the potential interactions between HCV and HIV drugs. ${ }^{33}$

\section{Clinical efficacy}

\section{Proof-of-principle studies}

Boceprevir was advanced to further clinical development after showing in a Phase I open-label combination study a median of $2.16 \log _{10} \mathrm{IU} / \mathrm{mL}$ viral load decrease in patients with chronic $\mathrm{HCV}$ infection (nonresponders to peg-IFN $\alpha+$ RBV therapy and infected with HCV genotype 1) in monotherapy at doses of $400 \mathrm{mg}$ three times daily for 14 days. ${ }^{34}$ The clinical efficacy of boceprevir in adult individuals with chronic HCV infection (genotype 1) has been established based on results from Phase II and Phase III studies (Table 2). These studies examined the use of boceprevir in SOC treatment-naïve and SOC treatment-experienced subjects (relapsers and nonresponders).

\section{Dose-ranging studies}

Boceprevir (100-400 $\mathrm{mg}$ twice daily and $400 \mathrm{mg}$ three times daily) showed dose-dependent inhibition of viral replication among 61 patients with $\mathrm{HCV}$ genotype 1 infection who had been previous nonresponders to SOC. ${ }^{28}$ In a multiple-dose, three-way crossover, Phase I study, combinations of boceprevir (200 $\mathrm{mg}$ or $400 \mathrm{mg}$ three times daily) and pegIFN $\alpha-2 b$ were safe and well tolerated in patients with genotype $1 \mathrm{HCV}$ infection who had previously not responded to SOC. ${ }^{35}$ Safety data therefore supported investigating higher doses of boceprevir to produce even higher anti-HCV activity in further studies.

\section{Phase II studies}

P03659 (NCT00160251) was a dose-ranging Phase II study evaluating boceprevir 100-800 $\mathrm{mg}$ three times daily + SOC in 357 genotype 1-infected patients enrolled in the US and Europe who had previously been nonresponders to SOC. The objectives were to determine the safe and effective dose range of boceprevir in combination with peg-IFN- $\alpha 2 b$ and whether the addition of RBV provided an additional benefit. During the trial, a protocol change was recommended for all patients to receive the highest dose of boceprevir $(800 \mathrm{mg}$ ) plus pegIFN- $\alpha 2 b$ and RBV. The study was completed in April 2007, establishing $800 \mathrm{mg}$ as the optimal dose of boceprevir and that $\mathrm{RBV}$ use is required to reduce viral breakthrough. ${ }^{36}$

A Phase II study (SPRINT-1) evaluated the SVR rates of triple therapy (boceprevir $800 \mathrm{mg}$ three times daily + peg-IFNo-2b + RBV for 24 or 48 weeks) in 520 treatmentnaïve patients infected with HCV genotype 1, compared with standard peg-IFN $\alpha-2 b+$ RBV therapy (Part I). Part II of SPRINT-1 included additional treatment arms $(\mathrm{n}=75)$ exploring reduced RBV dose (Table 2). Final results of SPRINT-1 were released in $2009^{37}$ and published in $2010 .{ }^{38}$ The triple-combination arm, with a treatment duration of 48 weeks, showed a significantly higher SVR rate $(67 \%)$ than the SOC control arm (38\%) and the reduced RBV arm (36\%). Rates of SVR were even higher (75\%) when a 4-week lead-in of SOC 
Table 2 Clinical trials with BOC (updated November I5, 20I0)

\begin{tabular}{|c|c|c|c|c|}
\hline Study & Patients & Arms & Results & Reference \\
\hline \multirow[t]{3}{*}{ Phase I } & $N=54$ & $\mathrm{BOC} n=36$ & Safety/PK profiling & $(26)$ \\
\hline & Healthy & Placebo $\mathrm{n}=18$ & & \\
\hline & volunteers & & & \\
\hline \multirow[t]{5}{*}{ Phase lb } & $N=26$ & Peg-IFN alone, I 4 days & $1.3 \log$ reduction & $(28)$ \\
\hline & SOC NR & BOC alone $200 \mathrm{mg}$ tid, 7 days & I.I log reduction & \\
\hline & HCV gt I & BOC alone $400 \mathrm{mg}$ tid, 7 days & I.6 log reduction & \\
\hline & 3-way crossover & Peg-IFN + BOC 200 mg tid + peg-IFN, I4d $(n=14)$ & $2.4 \log$ reduction & \\
\hline & & Peg-IFN + BOC $400 \mathrm{mg}$ tid + peg-IFN, I4d $(n=12)$ & $2.9 \log$ reduction & \\
\hline P03659 & $N=357$ & Dose-finding & I4\% SVR with BOC & $(34)$ \\
\hline NTC00I6025I & SOC NR & BOC I00-800 mg + peg-IFN & $400 \mathrm{mg}+$ peg-IFN + RBV & \\
\hline Phase II & HCV gt I & BOC $100-800 \mathrm{mg}+$ peg-IFN + RBV & & \\
\hline SPRINT-I & $N=595$ & Part I & & $(36)$ \\
\hline NTC00423670 & SOC naïve & Peg-IFN + RBV 48 wk & $38 \%$ SVR & \\
\hline \multirow[t]{7}{*}{ Phase II } & HCV gt I & Peg-IFN + RBV + BOC 800 mg tid, 24 wk (4 wk LI) & $56 \%$ SVR & \\
\hline & & Peg-IFN + RBV + BOC 800 mg tid, 44 wk (4 wk LI) & $75 \%$ SVR & \\
\hline & & Peg-IFN + RBV + BOC 800 mg tid, 28 wk & $58 \%$ SVR & \\
\hline & & Peg-IFN + RBV + BOC 800 mg tid, 48 wk & $67 \%$ SVR & \\
\hline & & Part II & & \\
\hline & & Peg-IFN + RBV + BOC 800 mg tid, 48 wk & $50 \%$ SVR & \\
\hline & & Peg-IFN + RBV + BOC 800 mg tid, 48 wk (low RBV) & $36 \%$ SVR & \\
\hline SPRINT-2 & $N=1097$ & Peg-IFN + RBV 800 mg tid, 48 wk & $40 \%(23 \%) *$ SVR & (38) \\
\hline NCT00705432 & SOC naïve & Peg-IFN + RBV + BOC 800 mg tid, 24 wk (4 wk LI) & $68 \%(42 \%) *$ SVR & \\
\hline \multirow[t]{2}{*}{ Phase III } & HCV gt I & RGT & & \\
\hline & & Peg-IFN + RBV + BOC 800 mg tid, 44 wk (4 wk LI) & $67 \%(53 \%) *$ SVR & \\
\hline RESPOND-2 & $\mathrm{N}=403$ & Peg-IFN + RBV + BOC 800 mg tid, 24 wk (4 wk LI) & $59 \%$ SVR & (37) \\
\hline NCT00910624 & SOC NR & RGT & & \\
\hline Phase III & HCV gt I & Peg-IFN + RBV + BOC 800 mg tid, 44 wk (4 wk LI) & $66 \%$ SVR & \\
\hline PO5685 AM2 & $N=198$ & Peg-IFN + RBV 800 mg tid, 48 wk & Pending (end 20I0) & http://clinicaltrials. \\
\hline NTC00845065 & SOC NR & Peg-IFN + RBV + BOC 800 mg tid, 44 wk (4 wk LI) & & gov/ct2/show/ \\
\hline Phase III & HCV gt I & & & NTC00845065 \\
\hline P06086 AMI & $N=685$ & Peg-IFN + RBV + BOC 800 mg tid, 44 wk (4 wk LI) & Pending (end 20II) & http://clinicaltrials. \\
\hline NTC01023035 & SOC naïve & RBV reduction & & gov/ct2/show/ \\
\hline \multirow[t]{2}{*}{ Phase III } & HCV gt I & Peg-IFN + RBV + BOC 800 mg tid, 44 wk (4 wk LI) & & NTC0I023035 \\
\hline & & EPO use & & \\
\hline P054I IAM3 & $N=99$ & Peg-IFN + RBV 800 mg tid, 48 wk & Pending (mid 20I2) & http://clinicaltrials. \\
\hline NCT00959699 & HCV/HIV coinfected & Peg-IFN + RBV + BOC 800 mg tid, 44 wk (4 wk LI) & & gov/ct2/show/ \\
\hline \multirow[t]{2}{*}{ Phase Illb } & SOC naïve & & & NCT00959699 \\
\hline & HCV gt I & & & \\
\hline P05063 & 3-year follow-up & Long-term safety, durability of virologic & Pending (mid 20I5) & http://clinicaltrials. \\
\hline NTC00689390 & of BOC-treated & response, and natural history of $\mathrm{HCV}$ & & gov/ct2/show/ \\
\hline \multirow[t]{3}{*}{ Phase III } & patients & sequence variants in patients treated & & NTC00689390 \\
\hline & & with $\mathrm{BOC}$ and peg-IFN with or & & \\
\hline & & without ribavirin & & \\
\hline
\end{tabular}

Note: *SVR in black patients.

Abbreviations: BOC, boceprevir; EPO, epoetin; gt, genotype; HCV, hepatitis C virus; LI, lead-in; peg-IFN, pegylated interferon; PK, pharmacokinetics; NR, nonresponders; RBV, ribavirin; SOC, standard of care; SVR, sustained virological response; tid, three times daily; RGT, response-guided therapy.

was administered before initiating boceprevir + peg-IFN $\alpha-2 b+$ RBV (Table 2). The lead-in phase aimed to limit the emergence of resistant virus by reducing viral replication before the start of boceprevir. These results indicate, as do the results of telaprevir trials, that adding a single DAA to current $\mathrm{HCV}$ treatment may significantly increase the SVR rates, but that
peg-IFN $\alpha+\mathrm{RBV}$ is still necessary for achieving SVR when using only one DAA. In addition, a lead-in phase of SOC before initiating boceprevir modestly reduces the chance for viral breakthrough, and thus the chance for the emergence of resistance (9/206 vs 19/210 viral breakthroughs in patients with or without lead-in, respectively). ${ }^{38}$ 


\section{Large safety and efficacy studies: Phase III}

Two Phase III trials (SPRINT-2 and RESPOND-2) evaluated 48-week treatment strategies with response-guided therapy: patients with no detectable HCV-RNA at week 8 and later stopped treatment at 28 weeks (SPRINT-2) or 36 weeks (RESPOND-2). Most updated data come from the presentation of final results in the 2010 annual meeting of the American Association for the Study of Liver Diseases. ${ }^{39,40}$

SPRINT-2 was performed in 1097 treatment-naïve patients infected with $\mathrm{HCV}$ genotype 1, divided into two cohorts of nonblack $(\mathrm{n}=938)$ and black $(\mathrm{n}=159)$ patients. Both cohorts were randomized to three arms: i) peg-IFN $\alpha-2 b+R B V$ for 48 weeks, ii) boceprevir + peg-IFN $\alpha-2 b+$ RBV response-guided, and iii) boceprevir + peg-IFN $\alpha-2 b+R B V$ for 44 weeks; all three arms included $a$ peg-IFN $\alpha-2 b+$ RBV lead-in phase during the first 4 weeks. Final results have been presented. For white patients, SVR rates were $67 \%$ and $68 \%$ in the response-guided arm and 48-week arm, respectively, compared with $40 \%$ with SOC for 48 weeks. ${ }^{40}$ For black patients, SVR rates were $42 \%$ and $53 \%$ in the response-guided and 48 -week arms, respectively, compared with $23 \%$ with SOC for 48 weeks. It was concluded that, in white patients, response-guided therapy allows treatment with boceprevir + peg-IFN $\alpha-2 b+$ RBV for only 24 weeks with similar efficacy to 44 weeks in treatmentnaïve subjects. ${ }^{40}$

RESPOND-2 was performed in 403 patients in whom previous SOC therapy failed, evaluating the two aforementioned treatment strategies. Final results have been presented. SVR rates were $59 \%$ and $66 \%$ in the response-guided and 48 -week arms, respectively, compared with $21 \%$ with SOC for 48 weeks. ${ }^{39}$ It was concluded that both response-guided therapy and boceprevir + peg-IFN $\alpha-2 b+$ RBV for 44 weeks were equally effective for SOC-experienced patients and that a 4-week peg-IFN $\alpha-2 b$ + RBV lead-in phase can be helpful in predicting which patients (those with less than $1 \log _{10}$ HCV-RNA first-month decline) have a very poor chance of response. ${ }^{39}$

P05685AM2 was a Phase III study investigating therapy with boceprevir + peg-IFN $\alpha-2 b+$ RBV for 44 weeks, with a previous lead-in of 4 weeks with SOC, in 198 patients infected with HCV genotype 1 who had previously failed SOC therapy.

P06086 AM1 (NTC01023035) is a Phase III trial including 685 treatment-naïve subjects infected with $\mathrm{HCV}$ genotype 1 to compare the effect on efficacy of erythropoietin use with RBV dose reduction for the management of anemia during treatment with boceprevir plus peg-IFN $\alpha-2 b$ + RBV therapy. Subjects who become anemic within the 48-week treatment period will be randomized to Arm 1 (RBV dose reduction) or Arm 2 (erythropoietin use) for management of the anemia. The total duration of therapy for all subjects will be 48 weeks. Completion is expected by the end of 2011 .

Finally, the 3-year follow-up study P05063 is being performed in patients previously treated in boceprevir clinical studies. Subjects will be followed for 3 years after the end of treatment to document maintenance of the antiviral response and to characterize the long-term safety of these new therapeutic regimens. Completion is expected by early 2015 (NCT00689390).

\section{Safety and tolerability}

In the dose-ranging Phase II study P03659 (NCT00160251), the most common AEs in subjects on boceprevir $(800 \mathrm{mg})$ plus peg-IFN $\alpha-2 b+$ RBV were fatigue (64\%), headache (55\%), anemia (42\%), nausea (41\%), and dysgeusia (26\%). ${ }^{36}$ In the Phase II SPRINT-1 trial, the most common AEs were also fatigue, nausea, headache, and anemia. The frequency of anemia was more common in all treatment groups receiving boceprevir + SOC compared with those receiving SOC alone, ${ }^{37,38}$ as with the telaprevir trials. ${ }^{41,42}$ In the SPRINT-2 and RESPOND-2 Phase III trials, anemia and dysgeusia were also more common in the boceprevir arms than in the SOC control arms. ${ }^{39,40}$ This raises concern about additive toxic effects. In SPRINT-1, epoetin alfa was used by $40 \%(236 / 595)$ of patients, and overall rates of AEs in Phase II studies of telaprevir and boceprevir suggest a slightly lower discontinuation rate in boceprevir-treated patients..$^{37,41,42}$ A Phase III trial to compare the effect on efficacy of erythropoietin use with $\mathrm{RBV}$ dose reduction for the management of anemia during the treatment with boceprevir plus SOC is ongoing. In the case of HCV/HIV coinfected patients, overlapping toxicity profiles and AEs will also be a concern when using HCV DAA agents together with antiretrovirals with higher risk for causing anemia, ${ }^{33}$ which could be increased by the concomitant use of SOC + boceprevir or telaprevir. A Phase IIb safety and efficacy study of boceprevir + SOC in patients coinfected with HIV and HCV is ongoing (NCT00959699).

In summary, administration of boceprevir three times daily added to twice-daily RBV plus once-weekly pegIFN $\alpha$ is a complicated dosing profile that may compromise adherence. Second-generation PIs need to minimize these problems by means of reductions in dosing intervals and perhaps advances in pharmacokinetic profiles. 


\section{Antiviral resistance}

Resistance of HIV to PIs caused by mutations in the viral protease is a hallmark of HIV protease-targeted therapies. ${ }^{43} \mathrm{By}$ analogy with HIV, it is expected that the widespread use of HCV DAAs will select for resistant viral isolates. Selection of HCV variants resistant to active-site PIs by amino acid substitutions in the HCV protease domain of NS3 was soon demonstrated, both in vitro and in clinical trials, during monotheraphy. ${ }^{44-51}$ Several amino acid positions have been associated with resistance, yet others may act as compensatory mutations restoring fitness loss of resistant isolates. Table 3 summarizes the available data to date on the emergence of $\mathrm{HCV}$ resistance to boceprevir and other NS3/4A PIs. The emergence of compound-specific $\mathrm{HCV}$ resistance is rapid in vivo, even within the first 2 weeks of exposure to a given DAA, ${ }^{52-56}$ though some resistant strains may show a reduced fitness. ${ }^{57,58}$ In a telaprevir Phase $\mathrm{Ib}$ trial, low levels of V36A/M, R155K/T, and A156V/T single mutations were associated with viral breakthrough during dosing of the inhibitor. These mutations impaired the binding of telaprevir to the viral protease, and single mutants were finally replaced by double V36A/M + R155K/T-resistant mutants, which were, however, shown to be sensitive to peg-IFN $\alpha+\mathrm{RBV}^{59,60}$ Available data on $\mathrm{HCV}$ resistance have been recently reviewed ${ }^{61} \mathrm{~A}$ major feature of resistance to $\mathrm{HCV}$ investigative PIs is crossresistance. The most relevant resistance mutations are substitutions in residues R155 and A156, which confer high levels of resistance to boceprevir and telaprevir and cross-resistance to most NS3 PIs. Other mutations at V36, T54, and V170 are associated with low levels of resistance to both telaprevir and boceprevir and some also with cross-resistance to other NS3 PIs. Of special concern is that some TVR-resistant variants remain detectable for up to 4 years after cessation of

Table 3 Mutations in the hepatitis C virus NS3/4A protease reported to induce resistance to hepatitis $C$ virus protease inhibitors in Phase III of clinical development (data from references ${ }^{61,70}$ )

\begin{tabular}{llll}
\hline & $\begin{array}{l}\text { BILN206I } \\
\text { (ciluprevir) }\end{array}$ & $\begin{array}{l}\text { SCH503034 } \\
\text { (boceprevir) }\end{array}$ & $\begin{array}{l}\text { VX950 } \\
\text { (telaprevir) }\end{array}$ \\
\hline In vitro & Q80R & T54 A & AI56S/V/T \\
(replicon & RI55Q & AI56S/T & \\
system) & AI56V/T & VI70A & \\
& DI68V/A & & \\
In vivo & No data & V36 A/L/M & V36A/M \\
(clinical & available & F43C/S & F43C \\
development) & & Q4IR & Q4IR \\
& & T54A/S & T54A/S \\
& & RI55 K/Q/T/M & RI55 K/TG//M/S/T \\
& & AI56S/V/T & AI56S/V/T \\
& & VI70A/T & VI70A \\
\hline
\end{tabular}

treatment, ${ }^{62}$ and that late relapse may occur even 24-36 weeks post-TVR + peg-IFN $\alpha+$ RBV therapy. ${ }^{63}$

With boceprevir, in monotheraphy or combined with peg-IFN $\alpha$, NS3 resistance mutations also emerged rapidly. ${ }^{64}$ After boceprevir monotherapy, high frequencies of resistant variants have been detected by clonal sequencing of $\mathrm{HCV}$ quasispecies in some patients after 1-year follow-up, ${ }^{65}$ and resistant mutations are rapidly selected during retreatment with boceprevir + peg-IFN $\alpha$ in some patients. ${ }^{66,67}$ In the SPRINT-1 trial, selection of resistance was assessed by population sequencing. As with telaprevir, the emergence of resistant viruses was also detected early on viral breakthrough (mainly mutations V36M, T54S, and R155K [ $>25 \%$ of samples] but also T54A, V55A, R155T, A156S, V158I, and V170A [5-25\% of samples] and V36A, V36L, and I170T $\left[<5 \%\right.$ of samples]). ${ }^{38}$ In addition, more than $25 \%$ of patients with viral breakthrough carried cross-resistant mutations to both boceprevir and telaprevir. ${ }^{38}$ Most updated data from the 3-year follow-up study P05063 (NCT00689390) indicate that at least one resistance mutation persists for more that 1 year in patients who did not achieve SVR in previous boceprevir trials $(\mathrm{n}=174) .{ }^{68}$ During follow-up, the most common resistance mutations were R155K (64\%), T54S (54\%), V36M (54\%), and T54A (22\%). Overall reversion to wild-type virus over a 2 -year period was seen in $59 \%$ of the patients, but T54S and R155K-carrying viruses reverted more slowly. The authors reported no late relapse in patients who did achieve SVR $(n=290)$ in this follow-up cohort. ${ }^{68}$

Available data also show that viral resistance mutations exist before treatment. $\mathrm{HCV}$ isolates are widely variable, and infections with $\mathrm{HCV}$ genotypes other than 1 account for a large number of chronic carriers worldwide. ${ }^{69}$ Thus, defining the variability of $\mathrm{HCV} \mathrm{NS3/4A} \mathrm{protease} \mathrm{in} \mathrm{natural} \mathrm{isolates}$ will be important to determine the potential selection of resistant strains, as happened with $\mathrm{HIV}^{43} \mathrm{~A}$ relevant polymorphism of NS3/4 proteases between HCV subtypes was found in sites associated either with resistance to NS3 inhibitors or with compensatory mutations after comprehensive analysis of more than 350 viral isolates worldwide (genotypes 1-6), with potential implications in the selection of viral resistance..$^{70}$ For instance, V170A (which confers low levels of resistance to boceprevir) was present in 184/275 HCV genotype 1 isolates, and D168V/A was an amino acid signature in HCV genotype 3 , explaining the reduced sensitivity of genotype 3 viruses to ciluprevir and potentially to other PIs. ${ }^{70}$ Later studies in a large number of patients detected variants at sites associated with resistance to HCV PIs in $5.5 \%$ and $1.4 \%$ of patients from the US, Switzerland, and Germany who were infected 
with subtypes 1 a or $1 \mathrm{~b}$, respectively, including the V36L/M and $\mathrm{R} 115 \mathrm{~K}$ variants associated with low- or high-level resistance. ${ }^{71}$ Bartels et al found that, in genotype 1-infected patients, $0.9 \%$ and $0.7 \%$ of viruses carried the V36M or $\mathrm{R} 155 \mathrm{~K}$ variants, respectively, and that patients with $\mathrm{R} 155 \mathrm{~K}$ virus appeared to have slower viral load declines during TVR + peg-IFN + RBV treatment than those with wt viruses. ${ }^{55}$ Finally, Gaudieri et al showed a prevalence of up to $4.4 \%$ of single resistance mutations to NS3 PIs in patients from Australia, Switzerland, and the UK and that, accounting for both NS3 protease and NS5b polymerase, the frequencies for single or combined resistance mutations were up to $21.5 \%$, $44.4 \%$, or $41.8 \%$ for subtypes $1 \mathrm{a}, 1 \mathrm{~b}$, or $3 \mathrm{a}$, respectively. ${ }^{72}$ Although the overall frequency of single resistance mutations is low in all these studies, this situation recalls the natural occurrence of drug-resistant viruses in treatment-naïve HIVinfected patients. ${ }^{73}$ In treatment-naïve HIV- and HBV-infected patients, naturally occurring polymorphisms that confer resistance to therapy can affect the treatment response. ${ }^{30,74}$ Major selected NS3 resistance mutants have been shown to hamper SVR on retreatment with TVR + SOC, to a different extent. Whereas four of five patients with the V36M resistance mutation selected during TVR trials achieved SVR, two of four patients with the $\mathrm{R} 155 \mathrm{~K}$ virus developed virological breakthrough, and 1 was lost to follow-up..$^{75}$

The high rate of mutation of $\mathrm{HCV}$ and its large population size are responsible for the extremely high genetic variability detected in HCV populations, defining HCV genotypes and quasispecies. ${ }^{76}$ The term "quasispecies" has usually been applied to describe highly heterogeneous viral populations composed of a swarm of closely related variants, any of which may have an ephemeral persistence in the population but can be rapidly selected. ${ }^{77}$ Whether minority resistant HCV variants to new DAAs (not detectable by direct population sequencing) are hidden within the complex genetic pool of HCV quasispecies circulating in a single infected patient is an important question, because viral quasispecies act as reservoirs of phenotypic virus variants. ${ }^{78}$ During therapy with boceprevir, Susser et al found that resistance mutations at six positions within the NS3 protease in the HCV quasipecies can be detected by way of clonal sequence analysis, although two weeks after the end of treatment with $400 \mathrm{mg}$ boceprevir twice or three times daily, the frequency of resistant variants declines and the number of wild-type isolates increases to $95 \%{ }^{64}$ It remains to be determined, however, whether these low-frequency resistant variants can be archived as compromising subsequent treatment options, because rapid selection of low-frequency resistant variants was observed during retreatment with boceprevir in combination with peg-IFN $\alpha-2 b$ in some patients. ${ }^{66}$

\section{Conclusion}

\section{The clinician's perspective}

Because the current SOC treatment cures around only $40 \%-50 \%$ of HCV genotype 1 -infected patients, currently, the pool of "hard-to-treat" and nonresponder patients has limited alternative options. In some, disease progression will advance to end-stages. In treatment-naïve patients, oral PIs that are being evaluated in Phase III trials, such as boceprevir, may eventually increase SVR rates to around $70 \%$, hence reducing the subset of nonresponders. In patients with previous failure to SOC treatment, the RESPOND-2 trial showed SVR rates around $60 \%$ with boceprevir + SOC treatment, compared with $21 \%$ with SOC retreatment for 48 weeks. These figures represent a substantial improvement in SVR rates, including in previous nonresponders, and the possibility to cure around $20 \%$ more patients infected with HCV genotype 1 than with current SOC.

Hence, over the coming years, the current SOC treatment is expected to change from peg-IFN $\alpha+\mathrm{RBV}$ to regimens based on peg-IFN $\alpha+\mathrm{RBV}$ together with one oral HCV PI, such as boceprevir. In this new setting, the decision that most clinicians face currently is to decide whether they should treat their patients immediately with the current SOC or, alternatively, whether they should wait for these newer therapies. The role for IL28B genotype testing will need to be placed in practice for predicting response to new therapies, because treatment failure to combinations of one oral HCV PI + peg-IFN $\alpha+$ RBV may be likely due to an insufficient response to pegIFN $\alpha+\mathrm{RBV}$, leading to reduced viral load decline. Finally, new issues will emerge with DAA-based therapies, especially for the emergence of resistance in nonresponder patients.

New regimens may force us to review the baseline predictors of response in order to help identify those patients to treat with SOC or with SOC + DAAs and how to tailor regimens and duration of therapy. For instance, patients with a favorable IL28B polymorphism genotype may be considered for SOC treatment ( $>65 \%$ anticipated SVR rate) before being considered for treatment with DAAs, to minimize the potential emergence of resistance. The toxicities related to the different classes of new molecules (alone, in combination, and in combination with current SOC) need to be investigated to establish risk and safety profiles of potential more potent new treatments with more than one DAA, which will substantially minimize the emergence of viral resistance. Finally, new treatment regimens with DAAs need to be investigated in 
special populations (such as cirrhotic transplant patients and HCV/HIV coinfected patients) who are most in need of improvements in the SVR rates of current SOC treatment.

\section{The virologist's perspective}

The emergence of viral resistance using a single DAA plus peg-IFN $\alpha+\mathrm{RBV}$ is anticipated in patients with viral breakthrough and will need to be properly evaluated and addressed, especially because cross-resistance to NS3 inhibitors is a common limitation that may compromise subsequent treatment alternatives. HCV is a highly variable virus with a daily virion production rate higher than that of HIV, and complete suppression of HCV replication will probably be needed to prevent the emergence of resistance. The emergence of viral resistance to new DAA-based therapies will be an important field of research in the coming years. The impact of pre-existing baseline resistant variants, the persistence of these resistant variants for a long time in treatment failures, and cross-resistance between different classes of DAAs need to be determined. The study of HCV sequences in key viral enzymes targeted by new drugs in development will certainly help to design genotypic and phenotypic assays to later determine predictive factors of SVR to newer therapies related to the viral sequence, as this is the case with HIV years after the initiation of antiretroviral therapies. As happens with HIV, HCV suppression will be more effective and viral resistance less likely to emerge if two DAAs are given in combination. It remains to be determined whether viral HCV reservoirs really exist, and whether new DAAbased HCV therapies can also archive resistant viruses in these reservoirs is unknown. Potential strategies to reduce viral breakthrough and resistance will be improving the adherence to treatment and the pharmacokinetics of DAAs, possibly optimizing once-daily dosing and ritonavir boosting of PIs, respectively. Available data suggest that peg-IFN $\alpha$ and RBV substantially contribute to reducing viral replication in DAA clinical trials. Therefore, it is expected that immunomodulators, such as IFN, and RBV will remain a necessary part of new HCV therapies. As in the early days of HIV infection, in the immediate future the decision that most clinicians will face will be to decide whether they should treat their patients immediately with the first new treatment regimen approved (probably peg-IFN $\alpha+\mathrm{RBV}$ together with only one HCV DAA) or alternatively whether they should wait for new approvals of combination therapies with two HCV DAAs with different mechanisms of action, combined with peg-IFN $\alpha+\mathrm{RBV}$ or not, to reduce the chances of viral breakthrough and the emergence of resistance. Although
HCV mutants that are resistant to a single DAA exist before therapy starts and can be rapidly selected, HCV isolates with mutations resistant to several DAAs are much less likely to occur. Ideally, combination therapy with a NS3/4A PI + NS5b inhibitor coadministered with peg-IFN $\alpha+$ RBV will probably be one of the most rational options for the future. However, the development of regimens combining DAAs to different viral targets needs to overcome potential antagonism and additive toxic effects.

Whether a dual DAA combination regimen will need coadministration with peg-IFN $\alpha+\mathrm{RBV}$ or RBV alone is an open question. Clinical trials combining $\mathrm{HCV}$ protease and polymerase inhibitors coadministered or not with SOC are underway (eg, NCT00801255: A Study of Combination Treatment With an HCV Polymerase Inhibitor [RO5024048] and an HCV Protease Inhibitor [RO5190591/Danoprevir] in Genotype 1 Chronic Hepatitis C Patients; NCT01225380: A Study of Response-Guided Duration of Combination Therapy With GS-9190, GS-9256, Pegasys ${ }^{\circledR}$ and Copegus ${ }^{\circledR}$ in Previously Untreated Subjects With Genotype 1 Chronic Hepatitis C; and NCT01080222: A Safety and Efficacy Study of the Combination of VX-222 and Telaprevir in Treatment-Naïve Subjects With Genotype 1 Chronic Hepatitis C Virus Infection).

\section{Acknowledgments}

This work was supported by the Fondo de Investigación Sanitaria, Instituto de Salud Carlos III, Spanish Ministry of Science (PS09/01707, PI10/00512, and CIBER-esp/CIBER-ehd), and by Generalitat Valenciana (AP-053/10). FXL holds a position supported by the Fondo de Investigación Sanitaria, Instituto de Salud Carlos III, Spanish Ministry of Science.

\section{Disclosure}

The authors report no conflicts of interest in this work.

\section{References}

1. Heathcote EJ. Antiviral therapy: chronic hepatitis C. JViral Hepat. 2007; $14: 82-88$.

2. Cuevas JM, Gonzalez-Candelas F, Moya A, Sanjuan R. Effect of ribavirin on the mutation rate and spectrum of hepatitis $\mathrm{C}$ virus in vivo. $J$ Virol. 2009;83:5760-5764.

3. Tam RC, Pai B, Bard J, et al. Ribavirin polarizes human T cell responses towards a Type 1 cytokine profile. J Hepatol. 1999;30:376-382.

4. Maylin S, Martinot-Peignoux M, Moucari R, et al. Eradication of hepatitis $\mathrm{C}$ virus in patients successfully treated for chronic hepatitis $\mathrm{C}$. Gastroenterology. 2008;135:821-829.

5. Cardoso A-C, Moucari R, Figueiredo-Mendes C, et al. Impact of peginterferon and ribavirin therapy on hepatocellular carcinoma: incidence and survival in hepatitis $\mathrm{C}$ patients with advanced fibrosis J Hepatol. 2010;52:652-657.

6. Asselah T, Estrabaud E, Bieche I, et al. Hepatitis C: viral and host factors associated with non-response to pegylated interferon plus ribavirin. Liver Int. 2010:30:1259-1269. 
7. Ge D, Fellay J, Thompson AJ, et al. Genetic variation in IL28B predicts hepatitis $\mathrm{C}$ treatment-induced viral clearance. Nature. 2009;461:399-401.

8. Lohmann V, Korner F, Koch J, et al. Replication of subgenomic hepatitis C virus RNAs in a hepatoma cell line. Science. 1999;285:110-113.

9. Lindenbach BD, Evans MJ, Syder AJ, et al. Complete replication of hepatitis C virus in cell culture. Science. 2005;309:623-626.

10. Wakita T, Pietschmann T, Kato T, et al. Production of infectious hepatitis $\mathrm{C}$ virus in tissue culture from a cloned viral genome. Nat Med. 2005;11:791-796.

11. Lamarre D, Anderson PC, Bailey M, et al. An NS3 protease inhibitor with antiviral effects in humans infected with hepatitis C virus. Nature. 2003; 426:186-189.

12. Hinrichsen $H$, Benhamou $Y$, Wedemeyer $H$, et al. Short-term antiviral efficacy of BILN 2061, a hepatitis C virus serine protease inhibitor, in hepatitis C genotype 1 patients. Gastroenterology. 2004;127: 1347-1355.

13. Li K, Foy E, Ferreon JC, et al. Immune evasion by hepatitis $\mathrm{C}$ virus NS3/4A protease-mediated cleavage of the Toll-like receptor 3 adaptor protein TRIF. Proc Natl Acad Sci U S A. 2005;102:2992-2997.

14. Lin C, Kwong AD, Perni RB. Discovery and development of VX-950, a novel, covalent, and reversible inhibitor of hepatitis $\mathrm{C}$ virus NS3.4A serine protease. Infect Disord Drug Targets. 2006;6:3-16.

15. Lawitz E, Rodriguez-Torres M, Muir A, et al. 28 days of the hepatitis C protease inhibitor VX-950, in combination with PEG-interferon-alfa-2a and ribavirin, is well-tolerated and demonstrates robust antiviral effects. Gastroenterology. 2006;131:950-951.

16. Malcolm BA, Liu R, Lahser F, et al. SCH 503034, a mechanismbased inhibitor of hepatitis $\mathrm{C}$ virus NS3 protease, suppresses polyprotein maturation and enhances the antiviral activity of alpha interferon in replicon cells. Antimicrob Agents Chemother. 2006;50: 1013-1020.

17. Bogen SL, Arasappan A, Bennett F, et al. Discovery of SCH446211 (SCH6): a new ketoamide inhibitor of the HCV NS3 serine protease and HCV subgenomic RNA replication. J Med Chem. 2006;49:2750-2757.

18. Liu R, Abid K, Pichardo J, et al. In vitro antiviral activity of SCH446211 (SCH6), a novel inhibitor of the hepatitis C virus NS3 serine protease. J Antimicrob Chemother. 2007;59:51-58.

19. Prongay AJ, Guo Z, Yao N, et al. Discovery of the HCV NS3/4A protease inhibitor (1R,5S)-N-[3-Amino-1-(cyclobutylmethyl)-2,3-dioxopropyl]-3- [2(S)-[[[(1,1-dimethylethyl)amino]carbonyl] amino]-3,3-dimethyl-1-oxobutyl]- 6,6-dimethyl-3-azabicyclo[3.1.0] hexan-2(S)-carboxamide (Sch 503034) II. Key steps in structure-based optimization. J Med Chem. 2007;50:2310-2318.

20. Seiwert SD, Andrews SW, Tan H, et al. 750 preclinical characteristics of ITMN-B, an orally active inhibitor of the HCV NS3/4A protease nominated for preclinical development. J Hepatol. 2006; 44:S278.

21. Reesink HR, Verloes K, Abou Farha A, et al. Safety of the HCV protease inhibitor TMC45350 in healthy volunteers and safety and activity in chronic hepatitis C infected individuals: a Phase I study [abstract]. 43rd Annual Meeting of the European Association for the Study of the Liver; Milan, Italy. 2008 Apr 23-27. J Hepatol. 2008:S28.

22. Ludmerer S, Graham D, Handt L, et al. Evaluation of MK-7009, a novel macrocyclic inhibitor of NS3/4A protease, in the Chimpanzee model of chronic hepatitis $\mathrm{C}$ virus infection. The Twenty-First International Conference on Antiviral Research; Montreal, Quebec, Canada. 2008 Apr 13-17 [abstract]. Antiviral Res. 2008:A23.

23. Achillion Pharmaceuticals I. Gilead and Achillion announce positive antiviral activity of NS4A antagonist in HCV, but discontinue GS 9132 (ACH-806) development, 2008. http://www.achillion.com. Accessed Jan 32011.

24. Boceprevir. Drugs in R\&D. 2010;10:203-210.

25. Merck. NDA for boceprevir, 2010. http://www.merck.com/newsroom/ news-release-archive/research-and-development/2010_0804.html. Accessed Jan 32011

26. Chen KX, Njoroge FG. The journey to the discovery of boceprevir: an NS3-NS4 HCV protease inhibitor for the treatment of chronic hepatitis C. In: Lawton G, Witty DR, editors. Progress in Medicinal Chemistry. 2010;49:1-36
27. Zhang JG, Gupta S, Rouzier R, et al. Single dose pharmacokinetics of a novel hepatitis $\mathrm{C}$ protease inhibitor, $\mathrm{SCH} 503034$, in an oral capsule formulation. J Hepatol. 2005;42:535.

28. Zeuzem S, Sarrazin C, Rouzier R, et al. Anti-viral activity of SCH 503034, a HCV protease inhibitor, administered as monotherapy in hepatitis $\mathrm{C}$ genotype-1 (HCV-1) patients refractory to pegylated interferon (PEG-IFN-alpha) [abstract]. J Hepatol. 2005;42:233A-234A.

29. Sarrazin C, Rouzier R, Wagner F, et al. SCH 503034, a novel hepatitis C virus protease inhibitor, plus pegylated interferon-2b for genotype 1 nonresponders. Gastroenterology. 2007;132:1270-1278.

30. Paredes R, Clotet B. Clinical management of HIV-1 resistance. Antiviral Res. 2010;85:245-265.

31. Kempf DJ, Klein C, Chen HJ, et al. Pharmacokinetic enhancement of the hepatitis C virus protease inhibitors VX-950 and SCH 503034 by codosing with ritonavir. Antivir Chem Chemother. 2007;18:163-167.

32. De Bruijne J, Bergmann JF, Reesink HW, et al. Antiviral activity of narlaprevir combined with ritonavir and pegylated interferon in chronic hepatitis C patients. J Hepatol. 2010;52:1590-1599.

33. Seden K, Back D, Khoo S. New directly acting antivirals for hepatitis $\mathrm{C}$ : potential for interaction with antiretrovirals. JAntimicrob Chemother. 2010;65:1079-1085. [Epub 2010 Mar 23].

34. Zeuzem S, Sarrazin C, Rouzier R, et al. Antiviral activity of SCH 503034, a $\mathrm{HCV}$ protease inhibitor, administered as monotherapy in hepatitis C genotype-1 (HCV-1) patients refractory to pegylated interferon (PEG-IFN-alpha) [abstract]. J Hepatol. 2005;10(Suppl.):233A-234A.

35. Sarrazin C, Rouzier R, Wagner F, et al. SCH 503034, a novel hepatitis C virus protease inhibitor, plus pegylated interferon alpha- $2 \mathrm{~b}$ for genotype 1 nonresponders. Gastroenterology. 2007;132:1270-1278.

36. Schiff E, Poordad E, Jacobson I, et al. Boceprevir (B) combination therapy in null responders (NR): response dependent on interferon responsiveness. J Hepatol. 2008;48:104.

37. Kwo P, Lawitz E, McCone J, et al. HCV SPRINT-1 final results: SVR from a Phase 2 study of boceprevir plus pegintron (Peg-IFN alpha-2b)/ $\mathrm{RBV}$ in treatment-naive subjects with genotype 1 chronic hepatitis $\mathrm{C}$ [abstract]. J Hepatol. 2009;50:S4.

38. Kwo PY, Lawitz EJ, McCone J, et al. Efficacy of boceprevir, an NS3 protease inhibitor, in combination with peginterferon alfa- $2 \mathrm{~b}$ and ribavirin in treatment-naive patients with genotype 1 hepatitis $\mathrm{C}$ infection (SPRINT-1): an open-label, randomised, multicentre Phase 2 trial. Lancet. 2010;376:705-716.

39. Bacon BR, Gordon SC, Lawitz E, et al. RESPOND-2 final results: high sustained virologic response among genotype 1 previous nonresponders and relapsers to peginterferon/ribavirin when re-treated with boceprevir plus PEGINTRON (peginterferon alfa-2b)/ribavirin [abstract]. Hepatology. 2010;52(Suppl.):216.

40. Bronowicki J, McCone J, Bacon BR, et al. Response-guided therapy (RGT) with boceprevir (BOC) + peginterferon alfa-2b/ribavirin (P/R) for treatment-naïve patients with hepatitis $\mathrm{C}$ virus $(\mathrm{HCV})$ genotype (G) 1 was similar to a 48-wk fixed-duration regimen with $\mathrm{BOC}+\mathrm{P} / \mathrm{R}$ in SPRINT-2 [abstract]. Hepatology. 2010;52(Suppl.):15.

41. McHutchison JG, Manns MP, Muir AJ, et al. Telaprevir for previously treated chronic HCV infection. N Engl J Med. 2010;362:1292-1303.

42. Hezode C, Forestier N, Dusheiko G, et al. Telaprevir and peginterferon with or without ribavirin for chronic HCV infection. $N$ Engl J Med. 2009;360:1839-1850.

43. Condra JH, Schleif WA, Blahy OM, et al. In vivo emergence of HIV-1 variants resistant to multiple protease inhibitors. Nature. 1995;374:569-571.

44. Trozzi C, Bartholomew L, Ceccacci A, et al. In vitro selection and characterization of hepatitis $\mathrm{C}$ virus serine protease variants resistant to an active-site peptide inhibitor. J Virol. 2003;77:3669-3679.

45. Lu L, Pilot-Matias TJ, Stewart KD, et al. Mutations conferring resistance to a potent hepatitis $\mathrm{C}$ virus serine protease inhibitor in vitro. Antimicrob Agents Chemother. 2004;48:2260-2266.

46. Lin C, Lin K, Luong YP, et al. In vitro resistance studies of hepatitis $\mathrm{C}$ virus serine protease inhibitors, VX-950 and BILN 2061: structural analysis indicates different resistance mechanisms. J Biol Chem. 2004;279:17508-17514. 
47. Lin $\mathrm{C}$, Gates $\mathrm{CA}$, Rao BG, et al. In vitro studies of cross-resistance mutations against two hepatitis $\mathrm{C}$ virus serine protease inhibitors, VX-950 and BILN 2061. J Biol Chem. 2005;280:36784-36791.

48. Mo H, Lu L, Pilot-Matias T, et al. Mutations conferring resistance to a hepatitis $\mathrm{C}$ virus (HCV) RNA-dependent RNA polymerase inhibitor alone or in combination with an HCV serine protease inhibitor in vitro. Antimicrob Agents Chemother. 2005;49:4305-4314.

49. Yi M, Tong X, Skelton A, et al. Mutations conferring resistance to SCH6, a novel hepatitis $\mathrm{C}$ virus NS3/4A protease inhibitor: reduced RNA replication fitness and partial rescue by second-site mutations. J Biol Chem. 2005;281:8205-8215.

50. Seiwert S, Hong J, Lim S, et al. Rev Antiviral Ther. 2007;1:56 (Abstract 52).

51. Zhou Y, Muh U, Hanzelka BL, et al. Phenotypic and structural analyses of hepatitis C virus NS3 protease Arg155 variants: sensitivity to telaprevir (VX-950) and interferon alpha. J Biol Chem. 2007;282:22619-22628.

52. McHutchison JG, Everson GT, Gordon SC, et al. PROVE1 study: results from a Phase 2 study of telaprevir with peginterferon plus ribavirin in treatment-naïve subjects with hepatitis $\mathrm{C}$ [abstract]. 43rd Annual Meeting of the European Association for the Study of the Liver; Milan, Italy. 2008 Apr 23-27. J Hepatol. 2008(Suppl.):S4.

53. Dusheiko GM, Hezode C, Pol S, et al. Treatment of chronic hepatitis C with telaprevir (TVR) in combination with peginterferon-alfa-2a with or without ribavirin: further interim analysis results of the PROVE2 study [abstract]. 43rd Annual Meeting of the European Association for the Study of the Liver; Milan, Italy. 2008 Apr 23-27. J Hepatol. 2008(Suppl.):S26.

54. Schiff E, Poordad F, Jacobson I, et al. Boceprevir combination therapy in null responders: response dependent on interferon responsiveness [abstract]. 43rd Annual Meeting of the European Association for the Study of the Liver; Milan, Italy. 2008 Apr 23-27. J Hepatol. 2008(Suppl.):S46.

55. Bartels DJ, Zhou Y, Zhang E, et al. Natural prevalence of HCV variants with decreased susceptibility to protease inhibitors in treatment-naïve subjects [abstract]. 43rd Annual Meeting of the European Association for the Study of the Liver; Milan, Italy. 2008 Apr 23-27. J Hepatol. 2008(Suppl.):S316.

56. Susser S, Welker MW, Zettler M, et al. Conal analysis of mutations selected in the HCV NS3 protease domain of genotype 1 non-responders treated with boceprevir (SCH203034) [abstract]. 43rd Annual Meeting of the European Association for the Study of the Liver; Milan, Italy. 2008 Apr 23-27. J Hepatol. 2008(Suppl.):S29.

57. Zeuzem S, Sarrazin C, Wagner F, et al. The HCV NS3 protease inhibitor SCH 503034 in combination with peg-IFN alpha-2b in the treatment of HCV-1 peg-IFN alpha-2b nonresponders: antiviral activity and HCV variant analysis. EASL 2006 [abstract]. J Hepatol. 2006(Suppl.):S35.

58. Sarrazin C, Kieffer TL, Bartels D, et al. Dynamic hepatitis C virus genotypic and phenotypic changes in patients treated with the protease inhibitor telaprevir. Gastroenterology. 2007;132:1767-1777.

59. Welsch C, Domingues FS, Antes I, et al. Molecular basis for VX-950 resistance [abstract]. J Hepatol. 2007;46:S30.

60. Kieffer TL, Sarrazin C, Miller JS, et al. Telaprevir and pegylated interferon-alpha-2a inhibit wild-type and resistant genotype 1 hepatitis $\mathrm{C}$ virus replication in patients. $J$ Hepatol. 2007;43:631-639.

61. Thompson AJ, McHutchison JG. Antiviral resistance and specifically targeted therapy for HCV (STAT-C). J Viral Hepat. 2009;16:377-387.
62. Susser S, Forestier N, Vermehren J, et al. Decline of detectable resistance mutations within the NS3 protease quasispecies during longterm follow-up after treatment with telaprevir [abstract]. J Hepatol. 2010;52:S300

63. Zeuzem S, Hezode C, Ferenci P, et al. Telaprevir in combination with peginterferon-alfa-2a with or without ribavirin in the treatment of chronic hepatitis C: final results of the PROVE2 study [abstract]. J Hepatol. 2008; $48: 243$

64. Susser S, Welsch C, Wang Y, et al. Characterization of resistance to the protease inhibitor boceprevir in hepatitis $\mathrm{C}$ virus-infected patients. Hepatology. 2009;51:1709-1718.

65. Susser S, Welker MW, Zettler M, et al. Clonal analysis of mutations selected in the HCV NS3 protease domain of genotype 1 non-responders treated with boceprevir (SCH503034) [abstract]. J Hepatol. 2008;48:S29.

66. Susser S, Forestier N, Welker MW, et al. Detection of resistant variants in the hepatitis $\mathrm{C}$ virus Ns3 protease gene by clonal sequencing at longterm follow-up in patients treated with boceprevir [abstract]. $J$ Hepatol. 2009;50:(51):57.

67. Vermehren J, Susser S, Karey U, et al. Clonal analysis of mutations selected in the HCV NS3 protease domain of genotype 1 nonresponders sequentially treated with boceprevir (SCH503034) and/ or pegylated interferon alpha-2b (PEG-IFN alpha-2B) [abstract]. J Hepatol. 2009;50:(51):57.

68. Vierling JM, Ralston R, Lawitz EJ, et al. Long-term outcomes following combination treatment with boceprevir plus pegintron/ribavirin $(\mathrm{P} / \mathrm{R})$ in patients with chronic hepatitis C, genotype 1 (CHC-G1) [abstract] J Hepatol. 2010;52:S470-S471.

69. Simmonds P. Genetic diversity and evolution of hepatitis C virus: 15 years on. J Gen Virol. 2004;85:3173-3188.

70. López-Labrador FX, Moya A, González-Candelas F. Mapping natural polymorphisms of hepatitis $\mathrm{C}$ virus NS3/4A protease and antiviral resistance to inhibitors in worldwide isolates. Antiviral Therapy. 2008; $13: 481-494$

71. Kuntzen T, Timm J, Berical A, et al. Naturally occurring dominant resistance mutations to hepatitis $\mathrm{C}$ virus protease and polymerase inhibitors in treatment-naive patients. J Hepatol. 2008;48:1769-1778.

72. Gaudieri S, Rauch A, Pfafferott K, et al. Hepatitis C virus drug resistance and immune-driven adaptations: relevance to new antiviral therapy. J Hepatol. 2009;49:1069-1082.

73. Najera I, Richman DD, Olivares I, et al. Natural occurrence of drug resistance mutations in the reverse transcriptase of human immunodeficiency virus type 1 isolates. AIDS Res Hum Retroviruses. 1994;10:1479-1488.

74. Zoulim F, Locarnini S. Hepatitis B virus resistance to nucleos(t)ide analogues. Gastroenterology. 2009;137:1593-1608.

75. Kieffer TL, Sarrazin C, Miller JS, et al. Telaprevir and pegylated interferon-alpha-2a inhibit wild-type and resistant genotype 1 hepatitis $\mathrm{C}$ virus replication in patients. J Hepatol. 2007;46:631-639.

76. Gonzalez-Candelas F, Lopez-Labrador FX. Clinical relevance of genetic heterogeneity in HCV. Future Virology. 2010;5:33-49.

77. Domingo E. Genetic variation and quasi-species. Curr Opin Genet Dev. 1992;2:61-63.

78. Najera I, Holguin A, Quinones-Mateu ME, et al. Pol gene quasispecies of human immunodeficiency virus: mutations associated with drug resistance in virus from patients undergoing no drug therapy. $J$ Virol. 1995;69:23-31.

Virus Adaptation and Treatment

\section{Publish your work in this journal}

Virus Adaptation and Treatment is an international, peer-reviewed open access journal focusing on the study of virology, viral adaptation and the development and use of antiviral drugs and vaccines to achieve improved outcomes in infection control and treatment. The journa welcomes original research, basic science, clinical \& epidemiological

studies, reviews \& evaluations, expert opinion and commentary, case reports and extended reports. The manuscript management system is completely online and includes a very quick and fair peer-review system, which is all easy to use. Visit http://www.dovepress.com/ testimonials.php to read real quotes from published authors. 